\title{
PENGARUH MODEL NUMBERED HEAD TOGETHER TERHADAP HASIL BELAJAR PKN KELAS IV SDN 10 BANDAR BUAT
}

\author{
Oleh : \\ Shari Ayu Rahma Yuni \\ shariayu09@gmail.com \\ reinita_reinita@yahoo.com \\ PGSD FIP Universitas Negeri Padang \\ Abstrak
}

Penelitian ini bertujuan untuk mengetahui pengaruh model Cooperative Learning Tipe Numbered Head Together terhadap hasil belajar PKn siswa di kelas IV. Jenis penelitian adalah quasy experiment dalam bentuk nonequivalent control group design. Populasi penelitian ini adalah seluruh siswa kelas IV SDN 10 Bandar Buat. Dengan teknik sampling jenuh diperoleh kelas $I_{\mathrm{A}}$ sebagai kelas eksperimen dan kelas $\mathrm{IV}_{\mathrm{B}}$ sebagai kelas kontrol. Hasil penelitian menunjukkan hasil t-test dengan taraf signifikan $(0,05)$ diperoleh $t_{\text {hitung }}=2,1>t_{\text {tabel }}=2,01$ yang mean kelas eksperimen 80,9 dan mean kelas kontrol 75,86 maka hipotesis $\mathrm{H}_{1}$ diterima.

Katakunci : Model NHT, Hasil Belajar.

This research aims at finding out the effects of applying the NHT model toward the students' learning outcomes of civics subject at class IV. This quasi experiment used the non-equivalent control group design. The population was all $4^{\text {th }}$ grade students of SDN 10 Bandar Buat. Samples were chosen by using the saturation sampling technique in which IVA acted as the experimental class and IVB as the control one. The research result shows that by using $t$-test with the level of significant of 0,05, tcount $=2,1>$ ttable $=$ 2,01 with the mean score of the mean score of the score of the experimental class $=80,9$ and the control class $=75,86$. Thus, the H1 hypothesis is accepted.

Keywords: the NHT Model, Learning Outcomes 


\section{A. PENDAhuluan}

Model pembelajaran cooperative merupakan salah satu model pembelajaran yang inovatif, karena pada dasarnya merupakan suatu strategi pembelajaran yang mengutamakan kerjasama dalam kelompok untuk mencapai tujuan pembelajaran.Hal tersebut dipertegas oleh Kurniasih (2015:117) yakni "Pembelajaran cooperative adalah sebuah strategi pembelajaran yang mengutamakan adanya kerjasama antar siswa dalam kelompok untuk mencapai tujuan pembelajaran, dimana siswa siswa dibagi ke dalam kelompok kecil dan diarahkan untuk mempelajari materi yang telah ditentukan”.

Model pembelajaran Cooperative juga merupakan strategi pembelajaran kelompok dimana yang tujuannya untuk dapat meningkatkan prestasi belajar siswa,dapat meningkatkan kemampuan hubungan sosial serta menumbuhkan sikap menerima kekurangan diri dan menghargai pendapat orang lain. Hal ini sesuai dengan pendapat Slavin (dalam Rusman,2011:205) bahwa "Penggunaan pembelajaran Cooperative dapat meningkatkan prestasi belajar siswa dan sekaligus meningkatkan hubungan sosial, menumbuhkan sikap toleransi dan menghargai pendapat orang lain.

Model pembelajaran Cooperative Learning Tipe NHT yang digunakan dalam pembelajaran memiliki langkah-langkah yang perlu dipahami dengan baik.Menurut Spencer (dalam Kunandar,2011:374) mengemukakan langkah-langkah model NHT, yaitu:

1) penomoran ( Numbering) yaitu guru memberikan para siswa menjadi beberapa kelompok atau tim yang beranggotakan 3-5 orang dan memberikan nomor sehingga setiap siswa dalam tim tersebut memiliki nomor yang berbeda, 2) pengajuan pertanyaan ( Questioning) yaitu guru mengajukan pertanyaan kepada, 3) berpikir bersama ( Head Together) yaitu para siswa berpikir bersama untuk mempelajari dan menyakinkan bahwa tiap orang mengetahui jawaban tersebut, 4) pemberian jawaban (Answaring) yaitu guru menyebut satu nomor dan para siswa dari tiap kelompok 
dengan nomor yang sama mengangkat tangan dan menyiapkan jawaban untuk seluruh kelas.

Selain memiliki langkah-langkah, model NHT juga memiliki beberapa keunggulan.Aris (2014:108-109) mengemukakan keunggulan model NHT, antara lain:

1) Setiap siswa menjadi siap, 2) dapat melakukan diskusi dengan sungguh-sungguh, 3) siswa yang pandai dapat mengajari siswa yang kurang pandai, 4) terjadi interaksi secara intens antarsiswa dalam menjawab soal, 5) tidak ada siswa yang mendominasi dalam kelompok karena ada nomor yang membatasi.

Kurniasih (2015:30) mengemukakan keunggulan NHT antara lain:

1) Dapat meningkatkan prestasi belajar siswa, 2) mampu memperdalam pemahaman siswa, 3) melatih tanggung jawab siswa, 4) menyenangkan siswa dalam belajar, 5) mengembangkan rasa ingin tahu siswa, 6) meningkatkan rasa percaya diri siswa, 7) mengembangkan rasa saling memiliki dan kerjasama, 8) setiap siswa termotivasi untuk menguasai materi, 9) menghilangkan rasa kesenjangan antara yang pintar dengan tidak pintar, 10) tercipta suasana gembira dalam belajar.

Berdasarkan keunggulan model NHT, dapat disimpulkan bahwa model NHT memiliki peranan yang sangat penting untuk meningkatkan hasil belajar PKn siswa Sekolah Dasar (SD). Penggunaan model NHT menyebabkan suasana pembelajaran PKn menjadi menyenangkan dan siswa menjadi aktif dalam proses pembelajaran. Jika pembelajaran sudah terasa menyenangkan, maka siswa lebih cepat mengerti dan memahami apa yang dipelajarinya, sehingga hasil belajar siswa pun dapat ditingkatkan.

Pembelajaran PKn di SD bertujuan untuk membentuk watak atau berkarakter warga negara yang baik dan membekali siswa dengan nilai tentang bagaimana bertingkah laku yang baik sebagai warga Negara Indonesia yang sesuai dengan Pancasila dan UUD 1945 serta mampu berpikir secara kritis rasional dan kreatif dalam menanggapi isu kewarganegaraan,berpartisipasi secara aktif bertanggung jawab dan 
bertindak secara cerdas dalam kegiatan masyarakat,berbangsa dan bernegara.

Seperti yang dikemukakan oleh Winarno (2013:19) Menyebutkan :

(1)berpikir secara kritis,rasional dan kreatif dalam menanggapi persoalan hidup dan isu kewarganegaraam,(2)berpartisipasi dalam segala bidang kegiatan,secara aktif dan bertanggung,sehingga bisa bertindak secara cerdas dalam semua kegiatan,(3)berkembang secara positif dan demokratis,sehingga mampu hidup bersama dengan bangsa-bangsa lainnya,(4)berinterkasi dengan bangsabangsa lain dalam peraturan dunia secara langsung atau tidak langsung dengan memanfaatkan teknologi informasi dan komunikasi. Hal ini akan mudah tercapai jika pendidikan nilai dan norma tetap ditanamkan pada siswa sejak usia dini karena jika siswa sudah memiliki nilai norma yang baik,maka tujuan untuk mencapai warga negara yang baik akan terwujudkan.

Berdasarkan observasi yang peneliti lakukan di SDN 10 Bandar Buat pada tanggal 21 dan 28 Juli 2017 peneliti menemukan permasalahan sebagai berikut1)penerapan pembelajaran PKn, guru kurang mengembangkan model pembelajaran yang inovatif (bervariasi) seperti model Cooperative Learning Tipe Numbered Head Together,2) Pembagian diskusi kelompok belajar siswa masih dengan urutan tempat duduk, bukan melihat pada kemampuan siswa,3) pada proses pembelajaran PKn kurang melibatkan siswa secara aktif dalam interaksi belajar mengajar, sehingga siswa kurang termotivasi dalam belajar sehingga suasana pembelajaran menjadi bosan.

Masalah yang ditemui peneliti diatas,agar menerapkan model pembelajaran NHT dalam pembelajaran PKn agar siswa lebih terlibat aktif dalam proses pembelajaran sehingga siswa senang dalam belajar, menumbuhkan sikap yang bertanggung jawab, dan dapat meningkatakan rasa percaya diri dengan demikian hasil belajar siswa semakin meningkat. Menurut Kurniasih (2015:30)"kelebihan dalam penggunaan model NHT dapat meningkatkan prestasi siswa,memperdalam pemahaman siswa,melatih bertanggungjawab,menyenangkan siswa dalam belajar, 
meningkatkan percaya diri, mengembangkan sikap kerjasama, siswa termotivasi untuk menguasai materi dan tercipta suasana gembiran dalam belajar.

Berdasarkan uraian diatas maka peneliti melakukan penelitian dengan judul "Pengaruh Penggunaan Model Cooperative Learning Tipe Numbered Head Together (NHT) Terhadap Hasil Belajar Siswa Pada Pembelajaran PKn di Kelas IV SDN 10 Bandar Buat Kota Padang”.

Tujuan penelitian ini adalah "Melihat pengaruh model Cooperative Learning Tipe Numbered Head Together (NHT) terhadap hasil belajar PKn siswa kelas IV Sekolah Dasar”.

\section{B. METODE PENELITIAN}

Dalam penelitian ini, digunakan pendekatan kuantitatif dalam jenis penelitian eksperimen. Dalam Sugiyono (2010:107) menyatakan bahwa "penelitian eksperimen adalah metode penelitian yang digunakan untuk mencari pengaruh perlakuan tertentu terhadap yang lain dalam kondisi yang terkendalikan."

Penelitian eksperimen yang dilakukan yaitu Quasy Eksperiment design (eksperimen semu). Penelitian ini menggunakan dua kelas sampel yaitu kelas eksperimen dan kelas kontrol dimana diberi perlakuan yang berbeda dengan materi atau bahan ajar yang sama. Sebelum diberi perlakuan yang berbeda terlebih dahulu kedua kelas sampel diberi tes awal untuk mengetahui keadaan awal adakah perbedaan antara kelompok eksperimen dan kelompok kontrol. Pada setiap akhir pembelajaran diberi tes akhir. Tujuannya adalah untuk mengetahui ada tidaknya pengaruh signifikan penggunaan model kooperatif tipe NHT terhadap hasil belajar PKn siswa dari kedua kelas sampel setelah diberi perlakuan yang berbeda, yaitu dengan cara membandingkan hasil belajar kelas eksperimen dengan kelas kontrol.

Populasi dalam penelitian ini adalah seluruh siswa di kelas IV SDN 10 Bandar Buat Kota Padang. Penelitian ini menggunakan teknik sampling jenuh dalam memilih sampel yang representatif dari populasi. Teknik 
sampling jenuh digunakan karena pada penelitian ini jumlah anggota populasi kurang dari 100 dan seluruh populasi dijadikan sampel.

Sebagaimana menurut Lestari (2015:111) "Sampling jenuh dimana semua anggota populasi dijadikan sampel”. Kelas yang dipilih yaitu kelas IVA sebagai kelas eksperimen dan IVB sebagai kelas kontrol SDN 10 Bandar Buat Kecamatan Lubuk Kilangan Kota Padang. Dengan pertimbangan yang ditinjau dari pretest yang hasil rata-rata rendah dijadikan sebagai kelas eksperimen dan untuk rata-rata tinggi dijadikan sebagai kelas kontrol.

Instrumen penelitian yang digunakan adalah soal tes hasil belajar.Soal tes hasil belajar berupa tes.Tes disusun berdasarkan kisi-kisi pada indikator yang terdapat dalam materi yang dipelajari.Suatu tes dikatakan layak digunakan atau belum maka ada beberapa hal yang perlu dianalisa dari soal-soal tersebut meliputi, validitas item tes hasil belajar, daya pembeda, indeks kesukaran tes, dan realibilitas soal.

Tes akhir yang diberikan pada kedua kelas sampel untuk menentukan hasil belajar PKn siswa.Teknik analisis data menggunakan uji t yang dilaksanakan setelah uji prasyarat analisis t-tes telah terpenuhi, rumus t-tes yang digunakan sebagai berikut:

$$
\mathrm{t}_{0}=\frac{M_{1}-M_{2}}{S E M_{1}-M_{2}}(\text { Sudijono, } 2015: 314)
$$

dimana :

$$
\mathrm{SE}_{\mathrm{M} 1-\mathrm{M} 2}=\sqrt{\mathrm{SE}_{\mathrm{M} 1}}{ }^{2}+\mathrm{SE}_{\mathrm{M} 2}{ }^{2}
$$

Untuk keperluan pengujian hipotesis, diperlukan rumus hipotesis statistik yaitu pada taraf signifikan $\alpha=0,05$ (5\%) dengan hipotasis yang akan diuji: 
$\mathrm{H}_{0}$ :Tidak terdapat pengaruh positif penerapan model Cooperative Learning Tipe Numbered Head Together (NHT) terhadap hasil belajar PKn siswa di kelas IV SDN 10 Bandar Buat.

$\mathrm{H}_{1}$ :Terdapat pengaruh positif penerapan model Cooperative Learning Tipe Numbered Head Together (NHT) terhadap hasil belajar PKn siswa di kelas IV SDN 10 Bandar Buat.

Dengan kriteria pengujian :

Jika $t_{\text {hitung }}<\mathrm{t}_{\text {tabel }}$ maka $\mathrm{H}_{0}$ diterima dan $\mathrm{H}_{1}$ ditolak

Jika $t_{\text {hitung }}>\mathrm{t}_{\text {tabel }}$ maka $\mathrm{H}_{0}$ ditolak dan $\mathrm{H}_{1}$ diterima

\section{HASIL PENELITIAN}

\section{Deskripsi Data Hasil Penelitian}

\section{a. Deskripsi data hasil pretest Kelas IVA}

Setelah diberi perlakuan, maka diadakan tes untuk mengetahui pengaruh dari model pembelajaran cooperative learning tipe NHT. Berikut sajian data hasil belajar siswa PKn. Untuk melihat nilai pretest hasil belajar PKn kelas IVA bisa dilihat distribusi frekuensi pada tabel 1 di bawah ini:

Tabel 1.Distribusi Frekuensi pretest kelas IVA

\begin{tabular}{|c|c|c|}
\hline Interval Nilai & Frekuensi & Frekuensi Kumulatif \\
\hline $36-45$ & 6 & 6 \\
\hline $46-55$ & 7 & 13 \\
\hline $56-65$ & 6 & 19 \\
\hline $66-75$ & - & 19 \\
\hline $76-85$ & 4 & 23 \\
\hline $86-95$ & 5 & 28 \\
\hline Jumlah & 28 & \\
\hline
\end{tabular}

Berdasarkan tabel 1 di atas, menunjukkan bahwa siswa yang memperoleh nilai interval 36- 45 sebanyak 6 siswa, pada interval 4655 sebanyak 7 siswa, pada interval 56- 65 sebanyak 6 siswa, pada interval 66- 75 sebanyak 0 siswa, pada interval 76- 85 sebanyak 4 siswa dan pada interval 86- 95 sebanyak 5 orang. kelas IVA 
berjumlah dengan 28 orang yang memperoleh nilai tertinggi 93 dan nilai terendah 36. Dari nilai kelas eksperimen diperoleh rata-rata nilai sebesar 61,36 nilai median 57,5 dan nilai modus 66,9.

Tabel 2. Distribusi Frekuensi pretest kelas IVB

\begin{tabular}{|c|c|c|}
\hline Interval Nilai & Frekuensi & Frekuensi Kumulatif \\
\hline $36-45$ & 4 & 4 \\
\hline $46-55$ & 4 & 8 \\
\hline $56-65$ & 4 & 13 \\
\hline $66-75$ & 6 & 19 \\
\hline $76-85$ & 6 & 25 \\
\hline $86-95$ & 4 & 28 \\
\hline Jumlah & 28 & \\
\hline
\end{tabular}

Berdasarkan tabel 2 di atas, menunjukkan bahwa siswa yang memperoleh nilai interval 36- 45 sebanyak 4 siswa, pada interval 4655 sebanyak 4 siswa, pada interval 56- 65 sebanyak 4 siswa, pada interval 66- 75 sebanyak 6 siswa, pada interval 76- 85sebanyak 6 siswa dan pada interval 86- 95 sebanyak 4 orang. Kelas IVB dengan jumlah anak 28 orang memperoleh nilai tertinggi 93 dan nilai terendah 36. Dari nilai kelas IVB diperoleh rata-rata nilai sebesar 65,04, median 67 dan nilai modus 75,5

Berdasarkan deskripsi hasil pretest pada tabel di atas, dapat diketahui hasil belajar kelas IVA lebih rendah daripada kelas IVB. Untuk lebih jelasnya dapat dilihat pada diagram di bawah ini

Gambar 1. Perbandingan Nilai Pretest Kelas IVA dan IVB

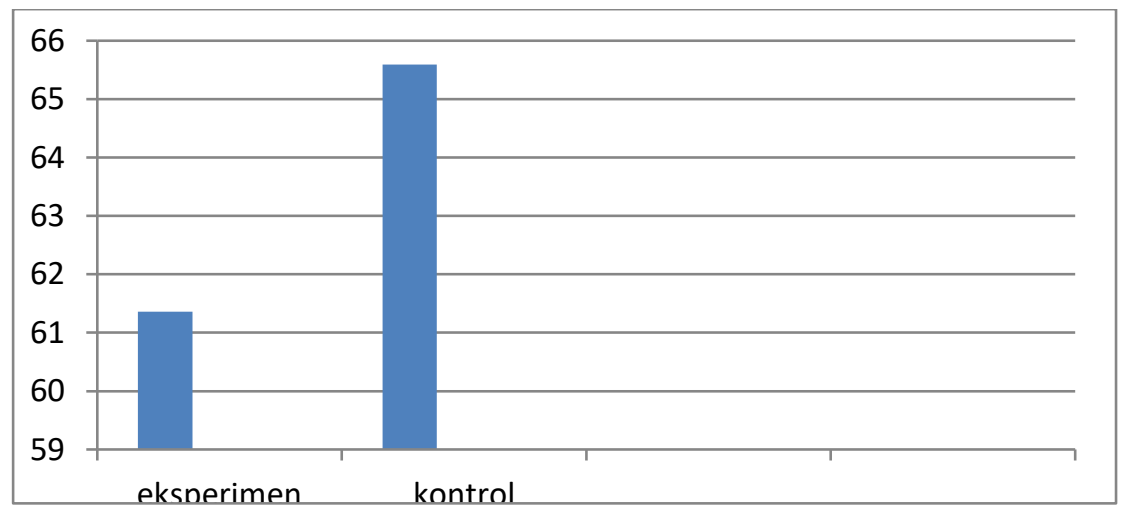




\section{b. Deskripsi data hasil posttest}

Untuk melihat nilai posttest hasil belajar PKn kelas eksperimen bisa dilihat distribusi frekuensi pada tabel 3 dibawah ini

Tabel 3.Distribusi frekuensi posttest kelas eksperimen

\begin{tabular}{|c|c|c|}
\hline Interval Nilai & Frekuensi & $\begin{array}{c}\text { Frekuensi } \\
\text { Kumulatif }\end{array}$ \\
\hline $63-68$ & 4 & 5 \\
\hline $69-73$ & 5 & 9 \\
\hline $74-79$ & 2 & 11 \\
\hline $80-85$ & 5 & 16 \\
\hline $86-91$ & 8 & 24 \\
\hline $92-97$ & 4 & 28 \\
\hline Jumlah & 28 & \\
\hline
\end{tabular}

Berdasarkan tabel 3 di atas, menunjukkan bahwa siswa yang memperoleh nilai interval 63 - 68 sebanyak 4 siswa, pada interval $69-$ 73 sebanyak 5 siswa, pada interval 74 - 79 sebanyak 2 siswa, pada interval 80 - 85 sebanyak 5 siswa, pada interval 86-91 sebanyak 8 siswa dan pada interval 92- 97 sebanyak 4 orang. Kelas Eksperimen dengan jumlah anak 28 orang memperoleh nilai tertinggi 96 dan nilai terendah 63. Dari nilai kelas eksperimen diperoleh rata-rata nilai sebesar 80,9 , median 88,5 dan nilai modus 82,5

Tabel 4. Distribusi frekuensi posttest kelas kontrol

\begin{tabular}{|c|c|c|}
\hline Interval Nilai & Frekuensi & $\begin{array}{c}\text { Frekuensi } \\
\text { Kumulatif }\end{array}$ \\
\hline $66-70$ & 11 & 11 \\
\hline $71-75$ & 4 & 15 \\
\hline $76-80$ & 5 & 20 \\
\hline $81-85$ & 4 & 24 \\
\hline $86-90$ & 2 & 26 \\
\hline $91-95$ & 2 & 28 \\
\hline Jumlah & 28 & \\
\hline
\end{tabular}

Berdasarkan tabel 4 di atas, menunjukkan bahwa siswa yang memperoleh nilai interval66 - 70 sebanyak 11 siswa, pada interval 71 75 sebanyak 4 siswa, pada interval 76 - 80 sebanyak 5 siswa, pada 
interval 81 - 85 sebanyak 4 siswa, pada interval 86 - 90 sebanyak 2 siswa, pada interval 91 - 95 sebanyak 2 orang. Kelas kontrol dengan jumlah anak 28 orang memperoleh nilai tertinggi 93 dan nilai terendah 66. Dari nilai kelas eksperimen diperoleh rata-rata nilai sebesar 7586, median 76,8dan nilai modus 85,5.

Berdasarkan deskripsi hasil posttest pada tabel diatas, dapat diketahui hasil belajar PKn kelas eksperimen lebih tinggi daripada kelas kontrol. Untuk lebih jelasnya dapat dilihat pada diagram batang berikut:

Gambar 2. Grafik Batang Perbandingan Hasil Posttest Kelas Sampel

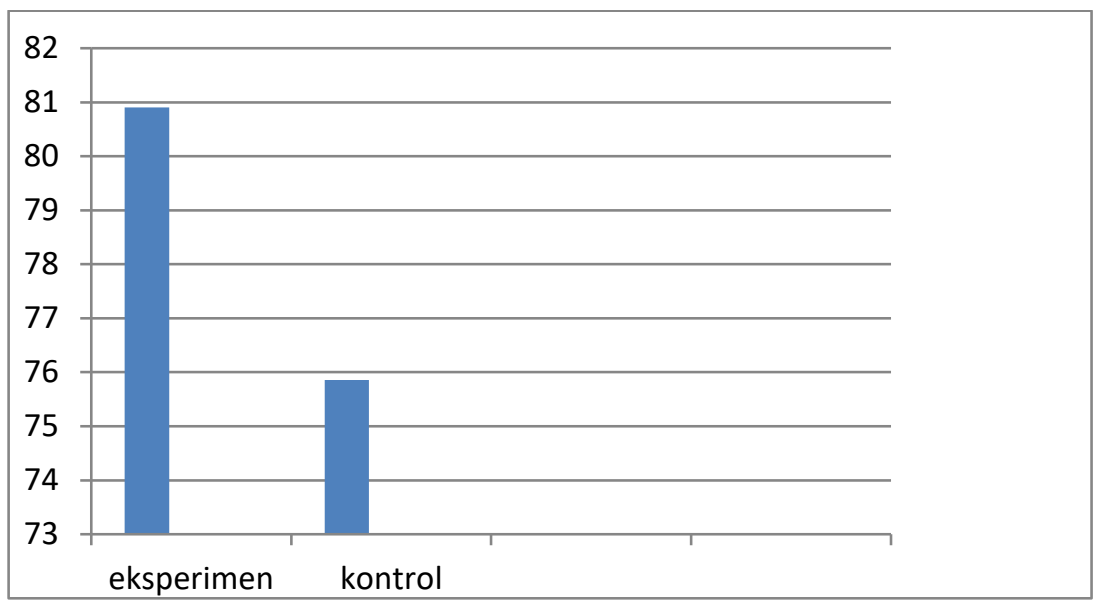

c. Perbandingan Nilai pretest dan posttest

Perbandingan nilai pretest kelas IVA dab IVB sedangkan pada postest antara kelompok kontrol dan kelompok eksperimen dapat dilihat pada tabel 5 di bawah ini.

Tabel 5. Perbandingan nilai pretest dan postest kelompok eksperimen dan kelompok kontrol

\begin{tabular}{|c|l|c|c|c|}
\hline \multirow{2}{*}{ No } & \multirow{2}{*}{ Kelompok } & \multicolumn{2}{|c|}{ Nilai Rata-Rata } & \multirow{2}{*}{ Peningkatan } \\
\cline { 3 - 4 } & & Pretest & Posttest & \\
\hline 1 & Eksperimen & 61,36 & 80,9 & 19,54 \\
\hline 2 & Kontrol & 65,04 & 75,86 & 10,82 \\
\hline
\end{tabular}


Berdasarkan tabel 4 di atas perbandingan nilai pretest dan postest kelompok kontrol dan kelompok eksperimen di atas dapat disajikan pada diagram 3berikut:

\section{Grafik 3. Diagram batang perbandingan nilai pretest IVA dan}

\section{IVB posttest kelompok eksperimen dan kelompok kontrol}

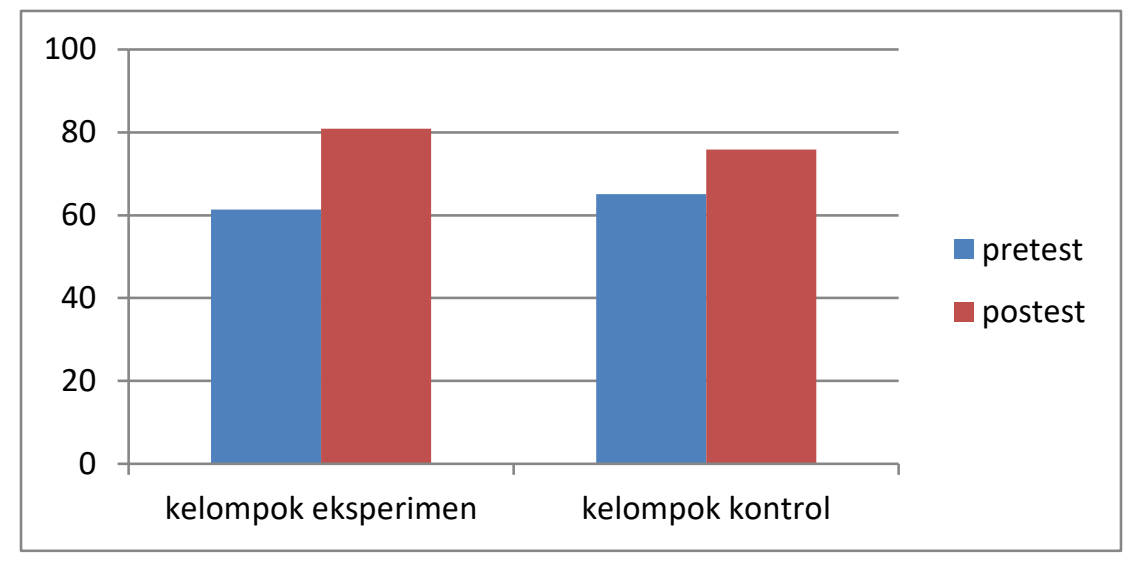

\section{Uji Persyaratan Analisis}

Uji persyaratan analisis dilakukan untuk melihat kesimpulan tentang data yang diperoleh dari hasil belajar siswa pada kedua kelas sampel.Sebelum melakukan uji hipotesis menggunakan rumus t-test terlebih dahulu dilakukan uji normalitas dan uji homogenitas variansi.

\section{a. Uji Normalitas Data}

Uji normalitas bertujuan untuk melihat data hasil belajar kedua kelas sampel berdistribusi normal atau tidak.Untuk melakukan uji normalitas dari data tes hasil belajar baik pada kelas eksperimen maupun kelas kontrol digunakan uji Kolmogrow Smirnov yang di hitung dengan bantuan Microsoft Excel. Setelah dilakukan perhitungan data pada kedua kelas sampel, maka diperoleh harga $\mathrm{D}_{\text {hitung }}$ dan $\mathrm{D}_{\text {tabel }}$ dengan taraf nyata 0,05 sebagai berikut : 
Tabel 6. Hasil uji normalitas data dari tes hasil belajar siswa kelas sampel

\begin{tabular}{|c|c|c|c|c|c|}
\hline $\begin{array}{c}\text { Kelas } \\
\text { Sampel }\end{array}$ & $\mathbf{N}$ & $\boldsymbol{D}_{\text {hitung }}$ & $\boldsymbol{D}_{\text {tabel }}$ & Kesimpulan & Keterangan \\
\hline Eksperimen & 28 & 0,142 & 0,2570 & $\begin{array}{l}D_{\text {hitung }} \\
<D_{\text {tabel }}\end{array}$ & $\begin{array}{c}\text { Data } \\
\text { Normal }\end{array}$ \\
\hline Kontrol & 28 & 0,1760 & 0,2570 & $\begin{array}{l}D_{\text {hitung }} \\
<D_{\text {tabel }}\end{array}$ & $\begin{array}{c}\text { Data } \\
\text { Normal }\end{array}$ \\
\hline
\end{tabular}

Dari tabel di atas dapat diketahui bahwa untuk kedua kelas sampel harga $\mathrm{D}_{\text {hitung }}$ dan $\mathrm{D}_{\text {tabel }}$ dengan demikian dapat disimpulkan bahwa data tes hasil belajar kedua kelas sampel berdistribusi normal pada tingkat kepercayaan $95 \%$.

\section{b. Uji Homogenitas Variansi}

Uji homogenitas variansi bertujuan untuk melihat data hasil tes belajar kelas eksperimen dan kelas kontrol mempunyai variansi yang homogen atau tidak.Dalam uji homogenitas digunakan uji $\mathrm{F}$.

Setelah dilakukan perhitungan, diperoleh data dari kedua kelas sampel sebagai berikut:

$$
\mathrm{F}=\frac{\text { Varians terbesar }}{\text { variansi terkecil }}
$$

Tabel 7. Distribusi Hasi Uji Homogenitas (Uji F) Tes hasil Belajar Kelas Sampel

\begin{tabular}{|c|c|c|c|c|c|}
\hline $\begin{array}{c}\text { Kelas } \\
\text { Sampel }\end{array}$ & N & Mean & Varian & F hitung & Keterangan \\
\hline Eksperimen & 28 & 80,9 & 103,91 & \multirow{2}{*}{$\mathrm{F}=\frac{103,91}{65,68}=$} & $\begin{array}{c}\text { Data } \\
\text { Homogen }\end{array}$ \\
\hline Kontrol & 29 & 75,86 & 65,68 & 1,582 & \\
\hline
\end{tabular}

Perhitungan harga $F$ dengan taraf nyata $\alpha=0,05$ dari tabel distribusi $\mathrm{F}$, ternyata diperoleh harga yaitu $\mathrm{F}_{\text {hitung }}<\mathrm{F}_{\text {tabel }} 1,582<1,905$ Dapat disimpulkan bahwa data hasil tes akhir kedua kelas sampel memiliki variansi yang homogen pada tingkat kepercayaan $95 \%$.

\section{Pengujian Hipotesis}

Setelah diperoleh bahwa kedua kelas sampel memiliki data tes hasil belajar PKn berdistribusi normal dan variansi yang homogen, maka 
untuk menguji hipotesis digunakan rumus t-tes. Sebelum dilakukan uji t, terlebih dahulu dihitung harga $\mathrm{SE}_{\mathrm{M} 1-\mathrm{M} 2}$, yaitu:

$$
\begin{aligned}
& \mathrm{SE}_{\mathrm{M} 1-\mathrm{M} 2}=\sqrt{\mathrm{SE}_{\mathrm{M} 1}{ }^{2}+\mathrm{SE}_{\mathrm{M} 2}{ }^{2}} \\
& \begin{aligned}
=\sqrt{ }(1,92)^{2}+(1,52)^{2} \\
=\sqrt{ } 3,68+2,31 \\
=\sqrt{ } 5,99 \\
=2,4
\end{aligned}
\end{aligned}
$$

Selanjutnya digunakan rumus sebagai berikut :

$$
\begin{aligned}
& \mathrm{t}_{0}=\frac{M_{1}-M_{2}}{S E M_{1}-M_{2}}(\text { Sudijono, } 2015: 314) \\
& =\frac{80,9-75,86}{2,4} \\
& =\frac{5,04}{2,4} \\
& =2,1
\end{aligned}
$$

Dari daftar distribusi $\mathrm{t}$ dengan taraf nyata $0,05 \mathrm{dan} \mathrm{dk}=54$, diperoleh $\mathrm{t}_{(0,05 ; 54)}=2,01$

Berdasarkan perhitungan di atas ternyata $t_{h i t u n g}>t_{(\alpha, d k)}$, berarti hipotesis $\mathrm{H}_{\mathrm{O}}$ ditolak. Dapat disimpulkan bahwa terdapat pengaruh yang signifikan modelJadi, $t_{\text {hitung }}>\mathrm{t}_{\text {tabel }}$ dengan 2,1>2,01 maka tolak $\mathrm{H}_{0}$ dan terima $\mathrm{H}_{1}$. Jadi dapat disimpulkan hipotesis dalam penelitian ini diterima yaitu terdapat pengaruh dalam penerapan model NHT terhadap hasil belajar PKn di kelas IV SDN 10 Bandar Buat.

\section{PEMBAHASAN}

Berdasarkan hasil penelitian yang peneliti lakukan kepada kelas yang diberikan perlakuan terdapat pengaruh hasil belajar siswa dengan menerapkan model NHT. Hal ini dapat dilihat dari dengan nilai rata-rata siswa kelas eksperimen yaitu (80,9). Berdasarkan hasil analisis data yang telah dilakukan diperoleh nilai $t_{\text {hitung }}=2,1 \geq t_{\text {tabel }}=2,01$ dengan $\alpha=$ 0,05. Maka Ha di terima, Ho ditolak.

Hasil belajar siswa yang diberikan perlakuan (kelas eksperimen) lebih tinggi daripada yang tidak diberikan perlakuan (kelas kontrol), dikarenakan siswa yang diberi perlakuan dengan model NHT merasa 
senang diberi kesempatan untuk mengemukakan pendapatnya. Selain itu siswa merasa paham dengan materi pelajaran yang disajikan dengan model NHT.

Pada kelompok eksperimen yang menggunakan model pembelajaran NHT, siswa dapat merasa paham dengan materi serta mampu untuk meningkatkan prestasi belajar. Hal ini diperkuat dengan pendapat Slavin (dalam Rusman, 2011:205) bahwa "Penggunaan pembelajaran kooperatif ini dapat meningkatkan prestasi belajar siswa dan sekaligus meningkatkan hubungan sosial, menumbuhkan sikap toleransi dan menghargai pendapat orang lain”.

Terlihat bahwa hasil belajar dengan model NHT yang dilakukan pada kelas eksperimen lebih baik dari dari hasil belajar yang diajarkan dengan yang tidak diberi perlakuan yaitu pada kelas kontrol, tentunya hal ini dapat ditinjau dari aktivitas yang dilihat. Bahwasanya aktivitas belajar dengan hasil belajar memiliki hubungan positif. Hal ini diungkapkan Jihad (2012:68) yang berpendapat bahwa "Semakin baik proses pembelajaran dan aktivitas belajar siswa dalam mengikuti proses pembelajaran, maka hasil belajar yang diperoleh siswa akan semakin tinggi sesuai dengan tujuan yang telah ditetapkan".

Dengan kata lain, terdapat pengaruh yang signifikan pada pengaruh penggunaan model Cooperative Learning tipe Numbered Head Together (NHT) terhadap hasil belajar siswa pada pembelajaran PKn kelas IV SDN 10 Bandar Buat.

\section{E. SIMPULAN DAN SARAN}

Berdasarkan hasil penelitian yang telah dikemukakan pada BAB IV terhadap masalah yang telah dikemukakan dalam penelitian ini,diperoleh nilai rata-rata post-testkelas eksperimen yang menerapkan pembelajaran dengan model NHT adalah 80.9 dan nilai rata-rata post-test kontrol yang menerapkan pembelajaran konvensional adalah 75,86. Berdasarkan hasil uji hipotesis menggunakan uji-t (t-test) diperoleh sehingga dapat disimpulkan bahwa taraf signifikan $5 \%(0,05)$ yang diperoleh $t$ hitung 
$(2,1)>\mathrm{t}$ tabel $(2,01)$ maka model Cooperative Learning Tipe Numbered Head Together (NHT) berpengaruh signifikan terhadap hasil belajar PKn siswa di kelas IV SDN 10 Bandar Buat Kota Padang Tahun Ajaran Pelajaran 2017/2018.

Berdasarkan kesimpulan di atas dapat dikemukakan beberapa saran untuk perbaikan hasil pembelajaran, antara lain: 1)bagi guru, agar dapat menggunakan model Cooperative Learning tipe Numbered Head Togetherdalam proses pembelajaran PKn di SD, karena penerapan model Cooperative Learning tipe Numbered Head Togetherdapat meningkatkan hasil belajar siswa,2)bagi kepala sekolah kiranya dapat memberi perhatian dan motivasi kepada guru terutama dalam upaya peningkatan hasil belajar siswa,3)penelitian ini tidak terlepas dari kekurangankekurangan. Untuk itu disarankan pada peneliti selanjutnya untuk lebih meneliti aspek-aspek lain yang dapat mengantisipasi kendala-kendala yang terjadi selama proses pembelajaran. 


\section{DAFTAR RUJUKAN}

Aris. 2014. 68 Model Pembelajaran Inovatif Dalam Kurikulum 2013. Yogyakarta Jakarta: Ar-Ruzz Media.

Jihad, Asep. 2012. Evaluasi Pembelajaran. Yogyakarta: Multi Pressindo.

Kunandar. 2011. Guru Profesional Implementasi Kurikulum (KTSP) dan Sukses Dalam Sertifikasi Guru. Jakarta: PT Raja Grafindo Persada.

Kurniasih, Imas. 2015. Ragam Pengembangan Model Pembelajaran untuk Peningkatan Profesionalitas Guru. Jakarta: Kata Pena.

Lestari, Yudhanegara. 2015. Penelitian Pendidikan Matematika. Bandung: PT Refika Aditama.

Rusman. 2012. Belajar dan Pembelajaran Berbasis Komputer Mengembangkan Profesionalisme Abad 21. Bandung: Alfabeta.

Sudijono, Anas. 2015. Pengantar Statistik Pemdidikan. Jakarta: PT Raja Grafindo Persada.

Sugiyono. 2012. Metode Penelitian Pendidikan (pendekatan kuantitatif,kualitatif,dan R\&D). Bandung: Alfabeta.

Winarno. 2013. Pembelajaran Pendidikan Kewarganegaraan: Isi, Strategi, dan Penilaian. Jakarta: Bumi Aksara. 